\title{
Reflexiones sobre la naturaleza del derecho urbanístico y propuesta de definición*
}

\section{Considerations on Urban Law Nature and a Definition Proposal}

Felipe Arbouin-Gómez a

Pontificia Universidad Javeriana, Colombia

farbouin@javeriana.edu.co

ORCID: http://orcid.org/0000-0003-1298-0192
DOI: https://doi.org/10.11144/Javeriana.vj138.rndu Redalyc: http://www.redalyc.org/articulo.oa?id=82559799003

Fecha de recepción: 18 Mayo 2018 Fecha de aprobación: 13 Junio 2018 Fecha de publicación: 30 Mayo 2019

\section{Resumen:}

A partir de la expedición de la Ley 9 de 1989, en el ordenamiento jurídico colombiano se afianzó una novedosa disciplina jurídica denominada derecho urbanístico, la cual ha sido presentada desde entonces desde diversas ópticas, ya sea como un conjunto de relaciones público-privadas, como parte general del derecho público, como una disciplina especial del Derecho Administrativo e incluso, como una nueva disciplina jurídica. Este artículo presenta una serie de reflexiones sobre la naturaleza, objetivos, principios y aplicación del derecho urbanístico y su ubicación dentro de las ciencias jurídicas, y culmina con la presentación de una propuesta de definición acorde con las materias estudiadas.

Palabras clave: Derecho urbanístico, derecho administrativo, legislación urbanística, desarrollo territorial, urbanismo.

\section{Abstract:}

The issue of the Ninth (9th) Law of 1989 consolidated a novel discipline within the Colombian legal system: Urban Law. Since then, such discipline has been presented from different perspectives, either as set of public and private relationships, as general component of Public Law, as a specific discipline of Administrative Law, or even as a brand new discipline. This article considers Urban Law's nature, purposes, principles and its enforcement; it also deals with its placement within the legal sciences. Finally, according to the previously studied subjects, we present a proposal of Urban Law's definition.

Keywords: Urban Law, Administrative Law, Urban Legislation, Territorial Development, Urbanism.

\section{Introducción}

En un artículo anterior ${ }^{1}$, hicimos referencia al derecho urbanístico como una disciplina muy joven dentro del ordenamiento jurídico colombiano, afianzada desde 1989 cuando la Ley $9^{2}$ de ese año consolidó un cuerpo normativo uniforme dedicado a la materia. Si bien en el artículo referido expusimos la evolución de esta disciplina desde la Colonia hasta la actualidad, no fue su objeto desarrollar una definición ni estudiar su naturaleza y aplicación. El propósito del presente artículo, a diferencia del antes mencionado, es presentar una serie de reflexiones sobre la naturaleza del derecho urbanístico y su ubicación dentro de las ciencias jurídicas, para finalmente proponer una definición acorde con los temas estudiados por esta disciplina.

Para efectos de lo anterior, con respecto al concepto a definir y no obstante ser estos tomados regularmente como sinónimos, en el presente artículo se utilizará el término derecho urbanístico por encima del de derecho urbano, por considerarse más preciso y definir de manera concreta la materia objeto de estudio.

Si bien en la doctrina colombiana y en la extranjera es común la utilización de los términos referidos, haciendo alusión al mismo concepto y dándole el mismo significado, se considera que el término derecho urbano podría, por su sentido etimológico, ser tomado como aquel derecho relativo a la urbs, es decir, a la ciudad $^{3}$, dejando de lado otros elementos que se encuentran comprendidos dentro del derecho urbanistico,

Notas de autor: 
como el suelo agrario, el medio ambiente rural, las infraestructuras de servicios y de transporte, las zonas de protección rural, ambiental y de riesgos, y temas que están por fuera de lo que estrictamente se entiende como urbe o ciudad.

Esta restricción al ámbito netamente urbano nos lleva a decantarnos por el término derecho urbanistico, el cual consideramos identifica de manera más precisa la materia objeto de estudio, al comprender no solamente el ámbito urbano o de ciudad, sino abarcando en su totalidad las materias que componen la disciplina del urbanismo ${ }^{4}$; el derecho urbanistico es una de las disciplinas que conforman esta materia ${ }^{5}$. Por lo anterior y se reitera, por considerarse un concepto más preciso y aplicable a los diferentes aspectos que conforman las materias estudiadas ${ }^{6}$, en el presente artículo se utilizará el término derecho urbanístico y se propondrá una definición del mismo, acorde con las temáticas objeto de estudio por tan particular disciplina.

Ahora bien y por la propia naturaleza de las materias que estudia y el régimen legal aplicable, así como la naturaleza pública de las normas que lo conforman, es posible advertir, desde ya, que el denominado derecho urbanistico hace parte de la disciplina general del derecho público.

Si bien es innegable su relación con otras ramas del derecho, hoy parece incuestionable que el derecho urbanistico hace parte del denominado derecho público y por lo tanto, debe ser estudiado según las particulares de esta rama. En palabras de EDUARDO CAICEDO-ESCOBAR:

la planificación de la ciudad, la racionalización del espacio, su redistribución, el volumen de edificabilidad, la determinación de los usos del suelo, la zonificación, etc., son funciones que por su particularidad ameritan normas especiales con un contenido, finalidad y poder decisorio de naturaleza pública; funciones que bien pueden no conciliar los intereses individuales, defendidos con criterio personal, y amparados en un derecho privado que solo es aplicable a las relaciones jurídicas entre particulares, mas no frente a las acciones del Estado ${ }^{7}$.

Por lo anterior, la pregunta que se plantea en el presente artículo no es si el derecho urbanistico hace parte o no del derecho público, como ya se afirmó, sino a qué rama de este pertenece.

Para dar respuesta a la pregunta planteada, en el presente artículo se analizan las diferentes concepciones existentes sobre el mismo, comenzando con aquellas que presentan el Derecho Urbanístico como un conjunto de relaciones público-privadas. Posteriormente, se analizan aquellas concepciones que lo presentan desde su finalidad, hasta llegar a aquellas que lo ubican dentro del Derecho Administrativo, con el fin de determinar si hace parte de alguna de las ramas tradicionales del derecho público o si, por el contrario, se trata de una nueva disciplina jurídica.

Por último, se presentan los objetivos y principios de la materia estudiada así como la importancia de diferenciar el derecho urbanistico de la legislación urbanistica ${ }^{8}$ y el desarrollo territorial ${ }^{9}$, para culminar con una propuesta de definición de derecho urbanístico acorde a su naturaleza.

El presente artículo, por tanto, presenta una serie de reflexiones sobre la naturaleza, aplicación y ubicación del derecho urbanistico dentro de las ciencias jurídicas, producto del análisis y el estudio efectuado por el autor en el marco de sus estudios de doctorado, para culminar con la presentación de una propuesta de definición, que si bien se construye en el ámbito del derecho colombiano, puede ser también aplicable en general a otras legislaciones.

\section{El derecho urbanístico como un conjunto de relaciones público-privadas}

La primera de las diferentes concepciones frecuentes sobre el derecho urbanistico es aquella que lo presenta como un conjunto de relaciones entre el Estado y los particulares, encaminadas a coordinar el ejercicio del derecho de propiedad privada con la legislación urbanistica.

Encontramos un claro ejemplo de esta concepción en aquella definición que describe el derecho urbanistico como: 
un conjunto de normas jurídicas, preponderantemente de derecho público, que regulan las relaciones entre los individuos y entre estos y el Estado, en función del aprovechamiento del espacio social; esto es, de todo el territorio susceptible de ser aprovechado para el establecimiento o desarrollo de asentamientos humanos ${ }^{10}$.

En el mismo sentido de la anterior, JOSÉ VICENTE BLANCO-RESTREPO postula como uno de los principales objetivos del derecho urbanistico el logro de un equilibrio entre la protección del interés general y el respeto a los derechos de los propietarios ${ }^{11}$, posición compartida igualmente por RODRIGO BUENOVÁSQUEZ $^{12}$ y ANTONIO CARCELLER-FERNÁNDEZ; este último en su obra Instituciones de derecho urbanistico lo describe como:

el conjunto de reglas a través de las cuales la Administración, en nombre de la utilidad pública, y los titulares del derecho de propiedad, en nombre de la defensa de los intereses privados, deben coordinar sus posiciones y sus respectivas acciones con vistas a la ordenación del territorio ${ }^{13}$.

En esta primera visión, consideramos oportuno subrayar lo planteado por el autor anteriormente citado, al afirmar que en el "derecho urbanístico están implicados varios intereses: por una parte, los generales, de seguridad, de fines sociales, que ha de tutelar la Administración, y, por otra, los intereses particulares, de los que, por regla general, son titulares los propietarios". Por esta razón, insiste CARCELLER-FERNÁNDEZ, el objeto del derecho urbanistico consiste en armonizar ambos intereses referidos a través de "fórmulas justas" e "instrumentos adecuados", que deben ser proporcionados por dicha disciplina ${ }^{14}$.

Si bien esta primera visión nos permite reafirmar que el denominado derecho urbanistico se sitúa dentro del derecho público, no la compartimos pues consideramos que el mismo va mucho más allá de ser un simple instrumento de coordinación o armonización de intereses públicos y privados. En nuestro concepto, la relación entre esta disciplina y el derecho civil tiene qué ver más con el hecho de que la legislación urbanistica impone una serie de limitaciones al ejercicio de los poderes de la propiedad - poderes de uso, goce y disposición consagrados en el artículo 669 del Código Civil—, como consecuencia de la función social de la propiedad y la consecuente prevalencia del interés general sobre el particular. Por tanto, podemos entender la legislación urbanistica como una limitación legal al derecho de propiedad inmobiliaria, es decir, como una restricción al ejercicio de los poderes que la ley otorga al titular del derecho real de dominio.

De esta manera, podemos señalar que el objetivo del derecho urbanistico o más precisamente de la legislación urbanistica, más que conciliar beneficios públicos y privados es lograr un desarrollo territorial adecuado, no solamente armonizando diferentes intereses sino imponiendo para ello una serie de limitaciones al ejercicio de las potestades otorgadas a los titulares del derecho de propiedad inmobiliaria por la legislación civil ${ }^{15}$.

Por todo lo anterior, reiteramos, no compartimos la concepción del derecho urbanístico como un instrumento de coordinación de diferentes intereses; por esta razón, pasaremos a referirnos a las diferentes definiciones de derecho urbanístico que se enfocan en la finalidad y los objetivos de esta disciplina y que, en nuestro concepto, abordan con mayor detalle la materia estudiada.

\section{El derecho urbanístico estudiado desde su finalidad}

En la doctrina especializada en urbanismo y sus ciencias afines, es frecuente encontrar definiciones de derecho urbanistico que, más que referirse a la naturaleza del mismo o de ocuparse de determinar su ubicación dentro de alguna de las ramas del derecho público, lo definen desde la óptica de sus objetivos o finalidad, aunque - valga la aclaración y en nuestro concepto- en muchos casos confundiéndola con los conceptos desarrollo territorial y/o legislación urbanistica.

Para comenzar con estas definiciones, a las que denominaremos finalistas, podemos citar aquella que, en consonancia con lo dicho en el numeral anterior, afirma que: 
el Derecho urbanístico va más allá de un conjunto de reglas a través de las cuales la administración y los titulares del derecho de propiedad coordinan sus posiciones y sus respectivas acciones respecto a la coordinación del territorio. En verdad, se trata de todo un ordenamiento jurídico particular, fuente legislativa específica que regula y define el dominio del suelo urbano, los derechos y obligaciones de los propietarios y las decisiones de la administración que inciden de manera notable sobre el desarrollo de las ciudades ${ }^{16}$.

De la concepción anterior, llama la atención la afirmación referente a que el derecho urbanístico es "todo un ordenamiento jurídico particular", que además es "fuente legislativa específica”, que parece sostener que se trata de una rama independiente del derecho público, que redefine la propiedad inmobiliaria, regula los derechos y obligaciones de sus titulares y las actuaciones de la administración en el marco del desarrollo urbano.

Con una visión similar, pero más amplia, MARÍA BLANCA BLANQUER-PRATS define el derecho urbanistico como un cuerpo autónomo específico, con materias específicas propias, pero que actúa de manera dependiente de otras leyes, relativas a la economía, medio ambiente, aguas, montes, costas, e incluso de otras como la legislación civil, penal, mercantil y el derecho administrativo, en este último caso por estar "imbuido de sus principios" y haber nacido dentro de su ámbito ${ }^{17}$. Interpretamos de esta manera, que la autora referida lo cataloga como una disciplina jurídica autónoma y específica, pero fundamentada en los principios del derecho administrativo, concepción que no compartimos por las razones consignadas en el numeral siguiente, pero que sin duda nos ayudará a acotar y definir la materia objeto de estudio.

Con una visión más pragmática, ADOLFO CARRETERO-PÉREZ define la materia referida como "esa parte del ordenamiento jurídico que regula el fenómeno social y técnico del urbanismo" ${ }^{18}$, visión similar a la que presenta JOSÉ RAMÓN PARADA-VÁZQUEZ al afirmar que se trata del "conjunto de normas reguladoras, grosso modo, de los procesos de ordenación del territorio y su transformación física a través de la urbanización y la edificación" ${ }^{19}$. Así mismo, GERD ALBERS manifestaba que por ser el derecho urbanistico una de las ciencias que conforman al urbanismo, es el encargado de establecer las reglas con que se deben planificar las ciudades, las herramientas, derechos, deberes y obligaciones de los agentes intervinientes, así como los límites establecidos a los mismos para evitar abusos y arbitrariedades ${ }^{20}$; sentido similar al utilizado por la Corte Constitucional, corporación que en 1995 presentó el derecho urbanístico como aquel que "se ocupa de atender los problemas contemporáneos del desarrollo y de otorgar a los municipios competencias relacionadas con la planeación de su entorno, con la acción urbanística del Estado, con los usos del suelo y con la calidad de la vida en las ciudades" ${ }^{21}$.

Ahora bien y utilizando dentro de la definición de derecho urbanistico los fines del urbanismo antes descritos, el tratadista venezolano ALLAN R. BREWER-CARÍAS lo definió como "la rama del derecho que tiene por objeto la ordenación del desarrollo urbano en función de los intereses, no solo individuales, sino colectivos del hombre, y de la salvaguardia de los recursos y de los valores ambientales; y todo por supuesto, con el fin de procurar un crecimiento armónico de los centros poblados y una distribución equilibrada en ellos de la población y de las actividades económicas" ${ }^{22}$. Similar visión presenta ALEKSEY HERRERA-ROBLES quien, al estudiar los límites legales y constitucionales de la propiedad en Colombia, menciona que el derecho urbanistico está compuesto por reglas jurídicas que se encargan de establecer límites al ejercicio del derecho de propiedad, fijar reglas al uso y demás condiciones generales de utilización de la propiedad inmueble, además de ordenar controles y acciones para garantizar en cumplimiento de las normas, la convivencia y la calidad de vida de los ciudadanos ${ }^{23}$. Es importante relevar el énfasis que la Corte Suprema de Justicia hace en este último aspecto, cuando al definir la materia objeto de estudio la describe como aquel "conjunto de normas que están destinadas al mejoramiento de la habitabilidad de cada una de las ciudades y municipios en donde se aplican dichas normas que tratan de disipar el caos de la alta expansión que se vive" ${ }^{24}$.

Por su parte, RICARDO ESTÉVEZ-GOYTRE apunta que el derecho urbanistico hace compatible el derecho a edificar - ius aedificandi- con el cumplimiento de las obligaciones establecidas a favor de la comunidad por la legislación urbanistica ${ }^{25}$; NELSON GEIGEL LOPE-BELLO añade la importancia de 
la asignación de recursos financieros y, en general, de los procesos de formulación y ejecución presupuestaria y la "captación de ingresos requeridos y de incentivos a las inversiones privadas de todo ello con miras a la materialización real de las obras contempladas en los planes de urbanismo" ${ }^{26}$.

MANUEL MEDINA DE LEMUS, por otro lado, enfoca su definición de derecho urbanistico desde la óptica de la transformación y utilización del suelo, y ratifica que el mismo está comprendido, entre otros, por las potestades atribuidas a los entes públicos dentro del régimen urbanístico del suelo, las políticas de desarrollo de los asentamientos humanos y los instrumentos técnicos para ello, los principios rectores del urbanismo y el orden de distribución de competencias entre el poder público estatal, autónomo y local ${ }^{27}$ ; esta visión es similar a la presentada por FERNANDO GALVIS-GAITÁN, quien lo define como aquel "conjunto de normas que regulan el urbanismo y la urbanización, planeando y ordenando el suelo, limitando la propiedad, haciendo prevalecer el interés general sobre el particular y distribuyendo equitativamente las cargas y los beneficios" 28 .

Por último, entre las definiciones que hemos llamado finalistas, JUAN FELIPE PINILLA-PINEDA y MAURICIO RENGIFO-GARDEAZÁBAL definen el derecho urbanistico como el "conjunto de normas de planificación, gestión y control mediante las cuales se ordena el territorio de las ciudades con el propósito de generar seguridad, salubridad y bienestar a sus habitantes y promover la realización efectiva de sus derechos, en el marco del desarrollo sostenible y la participación democrática" ${ }^{29}$.

Las anteriores concepciones, que ubican la disciplina objeto de estudio dentro del derecho público, tienen como común denominador su concepción finalista, en la mayoría de los casos enfocada al cumplimiento de los fines del urbanismo y el desarrollo territorial. Lo anterior —si bien en nuestra opinión más que definiciones de derecho urbanistico se trata de definiciones de legislación urbanistica o desarrollo territorial - nos permite observar con claridad la innegable relación que existe entre el urbanismo, la legislación urbanistica, el desarrollo territorial, el derecho urbanistico y el planeamiento urbano, estas dos últimas disciplinas consideradas como auxiliares de la primera.

Si bien algunas de las definiciones planteadas catalogan el derecho urbanistico como una rama autónoma del derecho público, en su mayoría, las concepciones presentadas lo enmarcan en el derecho administrativo, posición que compartimos en su totalidad. En nuestro concepto, el derecho urbanistico hace parte del derecho administrativo y, por lo tanto, está ligado a los principios y fundamentos de este, tal como se presentará a continuación.

\section{El derecho urbanístico como parte del derecho administrativo}

Para comenzar este numeral, es importante anotar que, aunque antes de 1989 muchas ciudades en Colombia ya contaban con normas de desarrollo del suelo de aplicación local, solo a partir de la expedición de la Ley 9 de 1989, tanto la jurisprudencia como la doctrina nacional comenzaron a utilizar de manera frecuente el término derecho urbanistico. Independientemente de si a partir de la expedición de esta ley surgió la disciplina referida o de si esta ya existía desde tiempo atrás en virtud de la legislación local existente en materia de urbanismo, la Ley mencionada, denominada Ley de reforma urbana, constituyó el primer cuerpo normativo de aplicación nacional, referente a lo que hemos denominado desarrollo territorial ${ }^{30}$.

Con respecto a su naturaleza y ubicación dentro de las ciencias jurídicas y poco tiempo después de ser sancionada la Ley 9 de 1989, EDUARDO CAICEDO-ESCOBAR se refería al derecho urbanistico como una disciplina incipiente, novedosa ${ }^{31}$ y en formación, la cual - decía desde entonces- hacía parte del derecho administrativo ${ }^{32}$ y surgía "como una rama especializada del derecho administrativo, bajo los principios seculares, directrices y limitantes que le impone la Constitución" ${ }^{33}$. 
Compartiendo plenamente la postura del autor referido sobre la naturaleza del derecho urbanistico, a continuación estudiaremos los diferentes enfoques referentes a esta posición, para lo cual y como punto de partida, tomaremos la definición de derecho administrativo expuesta por JAIME ORLANDO SANTOFIMIO-GAMBOA ${ }^{34}$, quien lo define como el "subsistema normativo o rama del derecho positivo que tiene por objeto el conocimiento y la regulación jurídica de los órganos, sujetos, funciones y finalidades de la administración pública y de sus relaciones con los asociados y con la comunidad" 35 .

En esta línea y en primer lugar, ALEKSEY HERRERA-ROBLES insiste en que el derecho urbanistico es "ante todo, un derecho administrativo, no solo por la naturaleza de las autoridades encargados de aplicarlo, sino por la naturaleza unilateral de las decisiones que lo afectan y por su propio contenido" ${ }^{36}$.

Por su parte, FRANCISCO JAVIER LUCAS-FERNÁNDEZ, al estudiar el concepto de derecho urbanistico, mostró las diversas maneras en que diferentes autores tratan su naturaleza. De esta manera, subraya que "Para [Aurelio] Guaita, su naturaleza es la de un Derecho Administrativo Especial. [Miguel Ángel] Núñez-Ruiz considera que el Derecho Urbanístico es formalmente Derecho administrativo, aunque materialmente pueda configurarse como un Derecho social, lo que posibilita, a su juicio, su independización del Derecho administrativo. Para [José] Martín-Blanco se trata de un Derecho especial que, participando de normas del Derecho Privado y del Derecho Administrativo, ofrece cierta peculiaridad que le separa de estos sin que de momento considere necesaria la clasificación o catalogación definitiva del mismo". Todo lo anterior, para concluir que si bien el estudio del derecho urbanistico debe realizarse en el marco del derecho administrativo, hay dentro de él innumerables normas de diferente naturaleza, ya sea civil, administrativa, procesal o tributaria. Con respecto a lo anterior y haciendo énfasis en las normas de naturaleza civil, este autor aclara que estas no pierden su naturaleza cuando hacen parte de la ordenación urbanística y por lo tanto, deben estudiarse en el ámbito del derecho privado ${ }^{37}$.

Ahora bien, otros autores haciendo énfasis en que el derecho urbanistico se rige por principios propios, adicionales a los del derecho administrativo, le otorgan una naturaleza especial. Entre ellos, EDUARDO GARCÍA DE ENTERRÍA y LUCIANO PAREJO-ALFONSO, quienes puntualizan que el "derecho urbanístico es una pertenencia de la llamada parte especial del Derecho administrativo", para afirmar más adelante que "no es una simple corroboración de las categorías dogmáticas ofrecidas por la parte general de la disciplina, sino un ámbito específico, dominado cada uno por principios propios" ${ }^{38}$.

En sentido similar, el autor argentino EDGARDO OSCAR SCOTTI puntualiza que el denominado derecho urbanístico no configura una rama autónoma del derecho administrativo ${ }^{39}$, no obstante reconocer los siguientes principios propios: "Principio de publicidad — único principio de los señalados que constituye un principio general del derecho administrativo-, principios de remisión e integración normativa, de delimitación de competencias, de edificabilidad, de compatibilidad y de perdurabilidad" ${ }^{40}$, para concluir que "un diverso aspecto que caracteriza al contenido de la disciplina es una integración por normas jurídicas de diverso carácter y jerarquía, pero que operan (o deben operar necesariamente) en forma interrelacionada conjugándose unas con otras para conformar integralmente la ordenación territorial en todas sus escalas" ${ }^{41}$.

Por último, posición que compartimos, ANTONIO CARCELLER-FERNÁNDEZ refiriéndose a la naturaleza de la disciplina estudiada, indica:

aunque se han formulado varias teorías (Derecho especial, rama jurídica interdisciplinaria y social, conjunto de normas de
naturaleza distinta, moderno capítulo del Derecho administrativo), la naturaleza del Derecho urbanístico es, básicamente,
la del Derecho Administrativo, como una pertenencia de su parte especial; lo que no obsta para que haya de exponerse y
deba comprenderse en relación con las instituciones del Derecho civil y, en particular, del derecho de propiedad privada.
La negación de la autonomía científica del Derecho Urbanístico no debe ser obstáculo para hacerlo objeto de una atención
especial dentro de una consideración de la actividad singular de la Administración ${ }^{42}$.

Con fundamento en las definiciones antes dadas y las diferentes posiciones expuestas por la doctrina, además de lo analizado en los acápites anteriores, concluimos que el derecho urbanistico hace parte del 
denominado derecho público. No se trata, en nuestro concepto, de una rama o disciplina nueva de este, sino que hace parte del derecho administrativo y con base en este es que debe aplicarse e interpretarse. Por su parte, la legislación urbanistica debe obedecer a los principios y fundamentos propios del derecho urbanistico y, por lo tanto, a aquellos que conforman el derecho administrativo, del cual este último hace parte.

Lo mismo ocurre por consiguiente en materia de desarrollo territorial. Por tratarse de una función pública, reglada y como se dijo anteriormente determinada por las competencias establecidas por la Constitución y la ley, su ejercicio está atado a los principios y fundamentos del derecho urbanistico y en caso de vacío, duda o inexistencia de normas específicamente aplicables en la materia, deberá darse aplicación a los postulados y principios propios del derecho administrativo, todo de conformidad con lo establecido por el artículo 8 de la Ley 153 de $1887^{43}$.

Para dar un ejemplo que nos ayude a ilustrar nuestra posición, podríamos tomar como supuesto un caso en el cual un juez de la República, dentro del estudio de una demanda de nulidad del plan de ordenamiento territorial de un municipio, no encuentre en la legislación urbanística una norma (ley) específica que le permita resolver el caso planteado. En este evento, el juez, teniendo en cuenta la naturaleza propuesta del derecho urbanistico, deberá buscar dentro del derecho administrativo la norma o el principio general que le permita resolver el caso en cuestión.

Para tomar otro ejemplo y en caso de dudas dentro del trámite de expedición de una licencia urbanística, pues por ejemplo la norma nacional de licencias urbanísticas no regula un tema en particular, la entidad correspondiente, por tratarse de una autoridad en los términos del artículo 2 del Código de Procedimiento Administrativo y de lo Contencioso Administrativo ${ }^{44}$, deberá remitirse a las normas generales sobre procedimiento administrativo y de esta manera, aplicar las reglas propias del derecho administrativo para resolver la solicitud. Al ser la expedición de este tipo de licencias una función administrativa y en consecuencia la entidad que las expide considerarse como una autoridad, esta y salvo que exista norma especial (ley) que establezca otro procedimiento, está en la obligación de dar aplicación a todo el procedimiento administrativo establecido en el citado Código ${ }^{45}$.

El derecho urbanistico, por tanto, hace parte del derecho administrativo y no obstante reconocer principios propios - como se verá más adelante-, se rige por los postulados y principios generales de este. De esta manera y una vez analizada la que en nuestro concepto es su naturaleza y ubicación dentro de las ciencias jurídicas, a continuación, presentaremos una serie de reflexiones sobre los objetivos de dicha disciplina para finalmente presentar como conclusión una propuesta de definición.

\section{Objetivos del derecho urbanístico}

Como ya se sostuvo, en nuestro concepto, el derecho urbanístico es una disciplina que hace parte del derecho administrativo y, por lo tanto, se enmarca en la rama general del derecho público, no obstante contener elementos propios de otras ramas de las ciencias jurídicas.

Para los efectos planteados en el presente numeral, consideramos importante reiterar la necesidad de diferenciar el derecho urbanistico de la legislación urbanistica y el desarrollo territorial ${ }^{46}$, teniendo en cuenta que el desarrollo territorial consiste en una función pública en cabeza de las diferentes entidades correspondientes, que hemos definido la legislación urbanistica como el conjunto de normas expedidas en materia de desarrollo territorial y que el derecho urbanistico es aquella parte del derecho administrativo que se encarga de estudiar tanto la legislación urbanística como todos los fenómenos jurídicos inherentes al desarrollo territorial. Por lo anterior, podemos advertir desde ya que no compartimos aquellas definiciones de derecho urbanistico que lo abordan como un conjunto de normas o aquellas que lo presentan desde los fines propios del desarrollo territorial, pues - consideramos - confunden los conceptos señalados. 
Realizada la anterior aclaración y con referencia a los objetivos de esta disciplina, cuya determinación nos permitirá construir una definición más precisa de la misma, comúnmente encontramos que tanto la doctrina como la jurisprudencia señalan como objetivos del derecho urbanistico lo que nosotros consideramos como objetivos de la legislación urbanistica y del desarrollo territorial. En este sentido, en sentencias T-508-92 ${ }^{47}$ y T-610-92 48 , la Corte Constitucional describe como objeto del derecho urbanistico regular los diversos aspectos del espacio público como la planeación local, la ordenación del espacio urbano, la regulación administrativa de dicho espacio, etc., lo que en palabras de CELSO ANTONIO BANDEIRA DE MELLO, RAÚL FRANCISCO NAVAS, RICARDO PABLO RECA, AUGUSTO L. REINHOLD y EDGARDO O. SCOTTI, consiste en orientar y dirigir el ordenamiento espacial a través del grado de especialización de los organismos actuantes ${ }^{49}$.

Así mismo, confundiendo - en nuestra opinión, reiteramos- los conceptos de derecho urbanistico, urbanismo y desarrollo territorial, ADOLFO CARRETERO-PÉREZ formula que el derecho, como una de las ciencias que conforman el urbanismo, tiene como papel dentro de este conjunto de ciencias - al ser el urbanismo, según el autor, una función claramente pública - dotar a la administración de normas y herramientas para ejercer correctamente el urbanismo, garantizar la búsqueda de su fin primordial, consistente en el bienestar de la comunidad y el mejoramiento de la calidad de vida de los habitantes del territorio ${ }^{50}$. Por lo anterior, el autor afirma que el urbanismo no es solo una ciencia de la administración, sino también una parte del derecho positivo y que es papel del derecho crear un ordenamiento jurídico específico que recoja las orientaciones de las otras ciencias auxiliares, para garantizar el interés general y el cumplimiento de los fines del urbanismo ${ }^{51}$.

Con mayor grado de desarrollo pero con un sentido similar a los anteriores y nuevamente etiquetando como objetivos de la disciplina estudiada los que nosotros consideramos son propios de la función pública del desarrollo territorial, JOSÉ RAMÓN PARADA-VÁZQUEZ indica los de "ordenar el conjunto del territorio, la urbanización y la intervención administrativa en el ius aedificandi", para señalar posteriormente que "entre la planificación del territorio y la edificación se produce un proceso intermedio, el de urbanización, que podemos definir como el de creación o modificación de espacios comunes de comunicación (plazas, calles, carreteras, infraestructuras en general) para la posterior erección de núcleos habitados, y que es el objeto central y esencial del Derecho Urbanístico" ${ }^{52}$.

Por su parte, JUAN FELIPE PINILLA-PINEDA nombra las materias que comprende el denominado derecho urbanistico, entre las cuales están la organización administrativa (competencias y potestades públicas; participación ciudadana, y garantías de los administrados), el régimen del suelo (que contempla la incidencia de la ordenación urbanística sobre el derecho de propiedad a través de la clasificación y la calificación de los terrenos), la gestión urbanística (sujetos actuantes, recuperación o distribución de plusvalías y régimen financiero del urbanismo) y la disciplina urbanística (intervención preventiva del uso del suelo y la edificación, medidas de protección de la legalidad urbanística, infracciones y sanciones y resarcimiento de daños e indemnización de perjuicios) ${ }^{53}$, materias que en nuestra opinión y al igual que lo planteado anteriormente, consisten en objetivos y herramientas propias de la administración en virtud de la función pública del desarrollo territorial, que junto con la legislación urbanistica y otros fenómenos relativos al urbanismo son objeto de estudio por la disciplina objeto de reflexión en el presente artículo ${ }^{54}$.

En conclusión, para delimitar y precisar los términos referidos, podemos afirmar que no obstante tener las disciplinas estudiadas una relación estrecha entre sí, tienen objetivos diversos. Por una parte, son objetivos últimos de la disciplina del urbanismo la búsqueda del mejoramiento de la calidad de vida de los habitantes, así como facilitar la satisfacción de sus necesidades, a través del planeamiento y desarrollo físico del territorio. Por su parte, son objetivos del desarrollo territorial la actuación, regulación y orientación del desarrollo físico del territorio por parte de las diferentes entidades públicas competentes, a través de los instrumentos 
de planeación, financiación, gestión y control establecidos en la ley, buscando el cumplimiento de los fines propios del urbanismo.

Adicionalmente y presentado en palabras de PEDRO PABLO MORCILLO-DOSMAN, posición que compartimos en su totalidad, es objetivo de la legislación urbanistica darles "fuerza legal a las políticas y medidas que adoptan las autoridades públicas para el ordenamiento territorial" 55 , a lo cual añadiríamos el de establecer los principios, reglas y limitaciones al ejercicio de la función pública del desarrollo territorial y las limitaciones al ejercicio de la propiedad inmobiliaria.

De acuerdo con todo lo anterior, y como conclusión del presente numeral, finalmente podríamos mencionar como objetivos del derecho urbanistico los de establecer los principios especiales aplicables al desarrollo territorial y por lo tanto, a la expedición, aplicación e interpretación de la legislación urbanistica, así como el estudio de esa normatividad y de los demás fenómenos jurídicos relativos al desarrollo territorial.

\section{Principios del derecho urbanístico}

A lo largo del presente artículo, hemos hecho referencia a que en nuestro concepto el derecho urbanistico hace parte del denominado derecho administrativo, pero cuenta con unos principios propios aplicables a las materias particulares objeto de estudio en esta disciplina. De conformidad con lo anterior y para formular una definición del concepto estudiado, a continuación se plantearán los principios aplicables al derecho urbanistico, los cuales consideramos nos brindarán los fundamentos teóricos faltantes para construir la definición anunciada.

En primer lugar y con referencia a estos principios, CARCELLER-FERNÁNDEZ declara que "los principios generales en los que el ordenamiento urbanístico tiene su fundamento y en los que ha de integrarse o interpretarse son, aparte de los de legalidad e igualdad, los de respeto del derecho a la propiedad privada y de delimitación del contenido de este derecho a través de su función social; a los que puede añadirse, según algunos, el de subsidiariedad" ${ }^{56}$.

Aunque consideramos acertados algunos elementos de la posición citada, es importante reiterar que en nuestro concepto el derecho urbanistico hace parte del derecho administrativo, por lo cual y de manera general, le son aplicables los principios propios de esa disciplina jurídica.

Por su parte y si bien podría pensarse que los principios de solidaridad, prevalencia del interés general sobre el particular y reparto equitativo de cargas y beneficios son principios especiales del derecho urbanistico, en nuestro concepto no lo son, pues obedecen a principios propios de la función pública del desarrollo territorial más que a principios especiales del derecho urbanistico. Afirmar que los tres principios referidos son principios del derecho urbanistico, sería ahondar en la confusión existente entre esta disciplina jurídica y la función pública del desarrollo territorial, tema analizado en páginas anteriores.

Ahora bien y como consecuencia de las materias tan particulares estudiadas por la disciplina jurídica analizada y en consonancia con lo expuesto por CARCELLER-FERNÁNDEZ y lo ampliamente desarrollado en el presente artículo, los principios especiales del derecho urbanístico son los de la función socialy la función ecológica de la propiedad, de los cuales se derivan el respeto al derecho de propiedad y la preservación del medio ambiente.

De esta manera y en conclusión, los principios particulares que deben guiar la actuación de la administración y los particulares en materia de derecho urbanistico y sobre los cuales la legislación urbanistica tiene su fundamento y ha de expedirse e interpretarse, son tanto los principios generales del derecho administrativo, es decir, los principios de legalidad, separación en el ejercicio de los poderes, control de la actividad estatal, responsabilidad, juez natural, prerrogativas públicas y coordinación ${ }^{57}$ y los principios de la función social y ecológica de la propiedad ${ }^{58}$. 
Fijados entonces los que consideramos son los principios de la materia estudiada y con el objeto ya de plantear o replantear una definición de derecho urbanistico, debemos recalcar que PEDRO PABLO MORCILLO-DOSMAN — cuya posición compartimos y hemos seleccionado para este último propósito final por ser la que más se acerca a nuestra concepción- define la disciplina jurídica referida como "la ciencia jurídica que estudia las normas que regulan las conductas humanas relacionadas con el uso y goce del suelo urbano y rural y el ordenamiento del territorio de los municipios, tanto en los aspectos sustantivos como de procedimiento y la administración de la aplicación de dichas normas" 59 .

\section{Conclusiones}

De conformidad con la anterior definición, con lo desarrollado en el presente artículo, una vez analizadas las diferentes concepciones sobre la materia, señalados su naturaleza y ubicación dentro de las ciencias jurídicas, sus objetivos y principios aplicables y a manera de conclusión, podemos definir el derecho urbanistico como aquella disciplina, parte del derecho administrativo, que se encarga del estudio de las normas, principios y demás fenómenos jurídicos relativos al urbanismo y al desarrollo territorial, tanto en su parte sustancial como procedimental y que establece los principios y fundamentos jurídicos con base en los cuales debe guiarse la actuación de la administración y de los particulares en esta materia y expedirse, aplicarse e interpretarse la legislación urbanistica.

\section{Bibliografía}

\section{Libros}

AFONSO CAVICHIOLI-CARMONA, PAULO, Violência $x$ cidade: o papel do direito urbanístico na violencia urbana (Marcial Pons Editora do Brasil, São Paulo, Brasil, Fundação Escola Superior do Ministério Público do Distrito Federal e Territórios, FESMPDFT, Brasília, 2014).

BLANQUER-PRATS, MARÍA BLANCA, Derecho urbanistico actual: la reforma por ley 8/1990, texto refundido de 1992, doctrina jurisprudencial vigente (Editorial Montecorvo, Madrid, 1993).

BOURDIN, ALAIN; LEFEUVRE, MARIE-PIERRE \& MELÉ, PATRICE (directeurs), Les règles du jeu urbain. Entre droit et confiance (Descartes \& Cie, Paris, 2006).

BREWER-CARÍAS, ALLAN RANDOLPH, Urbanismo y propiedad privada (Editorial Jurídica Venezolana, Caracas, 1980). Disponible en: http://allanbrewercarias.net/Content/449725d9-f1cb-474b-8ab2-41efb849fea5/Conte nt/II.1.35.pdf

CAICEDO-ESCOBAR, EDUARDO, Reforma urbana, espacio institucional para la ciudad (Biblioteca Jurídica Diké, Superintendencia de Notariado y Registro, Bogotá, 1990).

CARCELLER-FERNÁNDEZ, ANTONIO, Instituciones de derecho urbanistico (5a ed., Editorial Montecorvo, Madrid, 1992).

CARCELLER-FERNÁNDEZ, ANTONIO, Introducción al derecho urbanistico (Editorial Tecnos, Madrid, 1992).

ESTÉVEZ-GOYTRE, RICARDO, Manual de derecho urbanistico, doctrina, legislación y jurisprudencia (Editorial Comares, Granada, 2005).

GALVIS-GAITÁN, FERNANDO, Manual de derecho urbanistico (Editorial Temis, Bogotá, 2014).

GARCÍA DE ENTERRÍA, EDUARDO \& PAREJO-ALFONSO, LUCIANO, Lecciones de derecho urbanistico (Editorial Civitas, Madrid, 1979).

LONJA DE PROPIEDAD RAÍZ DE BOGOTÁ, Compilación de derecho urbanistico (Sello Editorial Lonja de Propiedad Raíz de Bogotá, Bogotá, 2008).

LOPE-BELLO, NELSON GEIGEL, Introducción al urbanismo y al derecho urbanistico (Equinoccio, Fundación Polar, Universidad Simón Bolívar, Caracas, 1993).

MEDINA DE LEMUS, MANUEL, Derecho urbanistico (J. M. Bosch Editor, Barcelona, 1999). 
MÉXICO, SECRETARÍA DE ASENTAMIENTOS HUMANOS Y OBRAS PÚBLICAS, Glosario de términos sobre asentamientos humanos (Secretaría de Asentamientos Humanos y Obras Públicas, México, 1978).

MORCILLO-DOSMAN, PEDRO PABLO, Derecho urbanistico colombiano - Historia, normativa y gestión (Editorial Temis, Bogotá, 2007).

PARADA-VÁZQUEZ, JOSÉ RAMÓN, Derecho urbanistico (Ediciones Jurídicas y Sociales, Madrid, 1999).

PAREJO-ALFONSO, LUCIANO; JIMÉNEZ-BLANCO Y CARRILLO, ANTONIO \& ORTEGA-ÁLVAREZ, LUIS, Manual de derecho administrativo, Volumen 2 ( $5^{\mathrm{a}}$ ed., Editorial Ariel, Barcelona, 1998).

PINILLA-PINEDA, JUAN FELIPE, Evolución del sistema urbanistico colombiano: reflexión pendiente desde el Derecho (Ediciones Uniandes, Bogotá, 2003).

PINILLA-PINEDA, JUAN FELIPE \& RENGIFO-GARDEAZÁBAL, MAURICIO, La ciudad y el derecho, una introducción al derecho urbano contemporáneo (Universidad de los Andes, Editorial Temis, Bogotá, 2012).

SANTOFIMIO-GAMBOA, JAIME ORLANDO, Compendio de derecho administrativo (Universidad Externado de Colombia, Bogotá, 2017).

SANTOFIMIO-GAMBOA, JAIME ORLANDO (director), Derecho urbanistico. Legislación y jurisprudencia (2a ed., Universidad Externado de Colombia, Bogotá, 2009).

SANTOFIMIO-GAMBOA, JAIME ORLANDO, Tratado de derecho administrativo: Introducción a los conceptos de la administración pública y derecho administrativo, Volumen 1 (Editorial Dvinni, Bogotá, 1996).

\section{Colaboración en obras colectivas}

BANDEIRA DE MELLO, CELSO ANTONIO; NAVAS, RAÚL FRANCISCO; RECA, RICARDO PABLO; REINHOLD, AUGUSTO L. \& SCOTTI, EDGARDO O., Limites jurídicos de la planificación urbanistica, en Derecho y planeamiento urbano, 429-462 (CELSO ANTONIO BANDEIRA DE MELLO, RAÚL FRANCISCO NAVAS, RICARDO PABLO RECA, AUGUSTO L. REINHOLD \& EDGARDO O. SCOTTI, Editorial Universidad, Buenos Aires, 1983).

SCOTTI, EDGARDO O., Contenido, caracteres y principios del derecho urbanistico, en Derecho y planeamiento urbano, 70-104 (CELSO ANTONIO BANDEIRA DE MELLO, RAÚL FRANCISCO NAVAS, RICARDO PABLO RECA, AUGUSTO L. REINHOLD \& EDGARDO O. SCOTTI, Editorial Universidad, Buenos Aires, 1983).

\section{Revistas}

ALBERS, GERD, Urbanismo y derecho urbanístico, 4 Revista de Derecho Urbanistico (1967). Disponible en: https:/ /libros-revistas-derecho.vlex.es/vid/urbanismo-derecho-urbanistico-120725

ARBOUIN-GÓMEZ, FELIPE, Derecho urbanístico y desarrollo territorial colombiano. Evolución desde la colonia hasta nuestros días, 124 Revista Vniversitas, 17-42 (2012). Disponible en: https://revistas.javeriana.edu.co/ind ex.php/vnijuri/article/view/14267

ARBOUIN-GÓMEZ, FELIPE, Evolución del derecho urbanistico y desarrollo territorial colombiano, 120 Práctica Urbanistica: Revista Mensual de Urbanismo, 52-62 (2013).

BLANCO-RESTREPO, JOSÉ VICENTE, La responsabilidad patrimonial de la administración pública por las limitaciones a la propiedad y la regulación de las "cesiones gratuitas" como forma de evadir dicha responsabilidad, 36 Revista de la Facultad de Derecho y Ciencias Politicas, Universidad Pontificia Bolivariana, 104, 47-66 (2006). Disponible en: https://revistas.upb.edu.co/index.php/derecho/article/view/5635/5232

CARRETERO-PÉREZ, ADOLFO, Precisiones sobre urbanismo y derecho urbanistico, 38 Revista de Derecho Urbanistico (1974). 
HERRERA-ROBLES, ALEKSEY, Conflictos urbanisticos en Barranquilla, 23 Revista de Derecho, Universidad del Norte, 69-87 (2005). Disponible en: http://rcientificas.uninorte.edu.co/index.php/derecho/article/view/2534 11657

HERRERA-ROBLES, ALEKSEY, Limites constitucionales y legales al derecho de dominio en Colombia, análisis desde el derecho público, 20 Revista de Derecho, Universidad del Norte, 57-81 (2003). Disponible en: http://rcientifica s.uninorte.edu.co/index.php/derecho/article/view/2890/1977

LUCAS-FERNÁNDEZ, FRANCISCO JAVIER, Naturaleza, fines y principios generales de la legislación urbanistica. Su influencia en el derecho privado, 3 Revista de Derecho Urbanistico (1967).

\section{Tesis}

BUENO-VÁSQUEZ, RODRIGO, Fundamentos del derecho urbanistico en Bogotá (Tesis de grado, Pontificia Universidad Javeriana, Bogotá, 1986).

\section{Normativa}

Colombia, Ley 57 de 1887, Código Civil. 2.867 Diario Oficial, 31 de mayo de 1873. Disponible en: http:// www.secretariasenado.gov.co/senado/basedoc/codigo_civil.html, http://www.funcionpublica.gov.co/eva/gestorn ormativo/norma_pdf.php?i=39535

Colombia, Ley 153 de 1887, que adiciona y reforma los Códigos nacionales, la ley 61 de 1886 y la 57 de 1887.7 .151 Diario Oficial, 28 de agosto de 1887. Disponible en: http://suin-juriscol.gov.co/viewDocument.asp?id=17929 50

Colombia, Ley 9 de 1989, por la cual se dictan normas sobre planes de desarrollo municipal, compraventa y expropiación de bienes y se dictan otras disposiciones. 38.650 Diario Oficial, 11 de enero de 1989. Disponible en: http://www.suin-juriscol.gov.co/viewDocument.asp?.ruta=Leyes/1565665

Colombia, Ley 388 de 1997, por la cual se modifica la Ley 9 de 1989, y la Ley 3 de 1991 y se dictan otras disposiciones. 43.091 Diario Oficial, 24 de julio de 1997, 43.127 Diario Oficial, 12 de septiembre de 1997. Disponible en: htt p://www.secretariasenado.gov.co/senado/basedoc/ley_0388_1997.html

Colombia, Ley 1437 de 2011, por la cual se expide el Código de Procedimiento Administrativo y de lo Contencioso Administrativo. 47.956 Diario Oficial, 18 de enero de 2011. Disponible en: http://www.secretariasenado.gov.c o/senado/basedoc/ley_1437_2011.html

Colombia, Ley 1801 de 2016, Código Nacional de Policía y Convivencia. 49.949 Diario Oficial, 29 de julio de 2016 Disponible en: http://www.secretariasenado.gov.co/senado/basedoc/ley_1801_2016.html

\section{Jurisprudencia}

Colombia, Corte Constitucional, Sentencia T-508-92, 28 de agosto de 1992, magistrado ponente Fabio Morón-Díaz. Disponible en: http://www.corteconstitucional.gov.co/relatoria/1992/t-508-92.htm

Colombia, Corte Constitucional, Sentencia T-610-92, 14 de diciembre de 1992, magistrado ponente Fabio MorónDíaz. Disponible en: http://www.corteconstitucional.gov.co/relatoria/1992/t-610-92.htm

Colombia, Corte Constitucional, Sentencia T-569-95, 1 de diciembre de 1995, magistrado ponente Fabio MorónDíaz. Disponible en: http://www.corteconstitucional.gov.co/relatoria/1995/t-569-95.htm

Colombia, Corte Suprema de Justicia, Sentencia 98 de 1998, 9 de noviembre de 1998, Expediente 1918, magistrado ponente Fabio Morón-Díaz. 


\section{Direcciones web}

http://dle.rae.es/?id=b8Ki852

http://dle.rae.es/?id=b8XhxR8

\section{Notas}

* Artículo de investigación

1 FELIPE ARBOUIN-GÓMEZ, Derecho urbanistico y desarrollo territorial colombiano. Evolución desde la colonia hasta nuestros dias, 124 Revista Vniversitas, 17-42 (2012).

2 Colombia, Ley 9 de 1989, por la cual se dictan normas sobre planes de desarrollo municipal, compraventa y expropiación de bienes y se dictan otras disposiciones. 38.650 Diario Oficial, 11 de enero de 1989.

3 La Real Academia Española define urbano como aquello perteneciente o relativo a la ciudad. http://dle.rae.es/?id=b8XhxR8

4 Para efectos del presente artículo, definimos urbanismo como aquella disciplina o conjunto de ciencias, disciplinas, conocimientos y principios, que se encarga del planeamiento, organización y desarrollo físico del territorio, cuya finalidad es la satisfacción de las necesidades de las personas, la protección del medio ambiente y el mejoramiento de la calidad de vida de sus habitantes.

5 Debemos advertir desde ya que, en nuestro concepto, entre las ciencias que componen el urbanismo, el derecho opera como elemento estructurador; sin embargo, no es propósito del presente artículo estudiar la relación del derecho con el urbanismo, sino estudiar la naturaleza del derecho urbanistico, su ubicación entre las ciencias jurídicas y proponer una definición precisa de este. Para un estudio detallado de la relación del derecho con el desarrollo urbanístico y el uso del derecho dentro de la acción urbanística y planificadora, se puede consultar: ALAIN BOURDIN, MARIE-PIERRE LEFEUVRE \& PATRICE MELÉ (directeurs), Les règles du jeu urbain. Entre droit et confiance (Descartes \& Cie, Paris, 2006).

6 La Real Academia Española define el término urbanistico como aquello perteneciente, relativo o de aplicación al urbanismo. $\mathrm{h}$ ttp://dle.rae.es/?id=b8Ki852

7 EDUARDO CAICEDO-ESCOBAR, Reforma urbana, espacio institucional para la ciudad, 14 (Biblioteca Jurídica Diké, Superintendencia de Notariado y Registro, Bogotá, 1990).

8 Para efectos del presente artículo, definiremos la legislación urbanística como aquel conjunto de normas jurídicas expedidas en materia de desarrollo territorial.

9 Así mismo y también para efectos del presente artículo, definiremos el desarrollo territorial como aquella función pública concertada, compuesta por un conjunto de normas, actuaciones, políticas y principios en cabeza de los municipios y distritos del país en coordinación con las demás entidades territoriales y nacionales competentes que, a través de herramientas de planeamiento, ejecución, financiación y control, busca la correcta ordenación física del territorio, garantizar el uso racional del suelo, el desarrollo equilibrado de las regiones y la protección del medio ambiente, del espacio público y del patrimonio cultural y natural, con el objetivo de mejorar la calidad de vida de los habitantes y facilitar la satisfacción de sus necesidades.

10 MÉXICO, SECRETARÍA DE ASENTAMIENTOS HUMANOS Y OBRAS PÚBLICAS, Glosario de términos sobre asentamientos humanos, 42 (Secretaría de Asentamientos Humanos y Obras Públicas, México, 1978).

11 JOSÉ VICENTE BLANCO-RESTREPO, La responsabilidad patrimonial de la administración pública por las limitaciones a la propiedad y la regulación de las "cesiones gratuitas" como forma de evadir dicha responsabilidad, 36 Revista de la Facultad de Derecho y Ciencias Politicas, Universidad Pontificia Bolivariana, 104, 47-66, 51 (2006).

12 RODRIGO BUENO-VÁSQUEZ, Fundamentos del derecho urbanistico en Bogotá, 62 (Tesis de grado, Pontificia Universidad Javeriana, Bogotá, 1986).

13 ANTONIO CARCELLER-FERNÁNDEZ, Instituciones de derecho urbanistico, 24, 25 (5a ed., Editorial Montecorvo, Madrid, 1992).

14 ANTONIO CARCELLER-FERNÁNDEZ, Introducción al derecho urbanistico, 17, 18 (Editorial Tecnos, Madrid, 1992). 
15 Es pertinente realizar una alusión al papel que el derecho policivo ocupa dentro del desarrollo territorial, a través de los diversos instrumentos de control urbanístico consagrados tanto en la Ley 388 de 1997 como en el Código Nacional de Policía y Convivencia. En ejercicio de la función pública del desarrollo territorial, la administración no solamente planea o ejecuta, sino que también a través de las autoridades de policía vigila el orden urbanístico y el cumplimiento de la denominada legislación urbanistica en los diferentes municipios y distritos del país.

16 LONJA DE PROPIEDAD RAÍZ DE BOGOTÁ, Compilación de derecho urbanístico, 13 (Sello Editorial Lonja de Propiedad Raíz de Bogotá, Bogotá, 2008).

17 MARÍA BLANCA BLANQUER-PRATS, Derecho urbanistico actual: la reforma por ley 8/1990, texto refundido de 1992, doctrina jurisprudencial vigente, 65 (Editorial Montecorvo, Madrid, 1993).

18 ADOLFO CARRETERO-PÉREZ, Precisiones sobre urbanismo y derecho urbanistico, 38 Revista de Derecho Urbanistico, $21,65(1974)$.

19 JOSÉ RAMÓN PARADA-VÁZQUEZ, Derecho urbanistico, 2 (Ediciones Jurídicas y Sociales, Madrid, 1999).

20 GERD ALBERS, Urbanismo y derecho urbanistico, 4 Revista de Derecho Urbanistico, 91, 92 (1967).

21 Colombia, Corte Constitucional, Sentencia T-569-95, 1 de diciembre de 1995, magistrado ponente Fabio Morón-Díaz.

22 ALLAN RANDOLPH BREWER-CARÍAS, Urbanismo y propiedad privada, 43 (Editorial Jurídica Venezolana, Caracas, 1980).

23 ALEKSEY HERRERA-ROBLES, Limites constitucionales y legales al derecho de dominio en Colombia, análisis desde el derecho público, 20 Revista de Derecho, Universidad del Norte, 57-81, 78-79 (2003).

24 Colombia, Corte Suprema de Justicia, Sentencia 98 de 1998, 9 de noviembre de 1998, Expediente 1918, magistrado ponente Fabio Morón-Díaz.

25 RICARDO ESTÉVEZ-GOYTRE, Manual de derecho urbanistico, doctrina, legislación y jurisprudencia, 14 (Editorial Comares, Granada, 2005).

26 NELSON GEIGEL LOPE-BELLO, Introducción al urbanismo y al derecho urbanistico, 115-118 (Equinoccio, Fundación Polar, Universidad Simón Bolívar, Caracas, 1993).

27 MANUEL MEDINA DE LEMUS, Derecho urbanistico, 13 (J. M. Bosch Editor, Barcelona, 1999).

28 FERNANDO GALVIS-GAITÁN, Manual de derecho urbanistico, 69 (Editorial Temis, Bogotá, 2014).

29 JUAN FELIPE PINILLA-PINEDA \& MAURICIO RENGIFO-GARDEAZÁBAL, La ciudad y el derecho, una introducción al derecho urbano contemporáneo, 14 (Universidad de los Andes, Editorial Temis, Bogotá, 2012).

30 FELIPE ARBOUIN-GÓMEZ, Evolución del derecho urbanistico y desarrollo territorial colombiano, 120 Práctica Urbanistica: Revista Mensual de Urbanismo, 52-62, 56-57 (2013).

31 PAULO AFONSO CAVICHIOLI-CARMONA en el mismo sentido señala que se trata de una disciplina jurídica relativamente nueva, que surge en virtud de las transformaciones sociales que vienen ocurriendo en los últimos tiempos como consecuencia del fuerte crecimiento urbano. PAULO AFONSO CAVICHIOLI-CARMONA, Violência x cidade: o papel do direito urbanistico na violencia urbana, 14 (Marcial Pons Editora do Brasil, São Paulo, Brasil, Fundação Escola Superior do Ministério Público do Distrito Federal e Territórios, FESMPDFT, Brasília, 2014).

32 EDUARDO CAICEDO-ESCOBAR, Reforma urbana, espacio institucional para la ciudad, 11 (1990).

$33 I b ., 14$.

34 No es propósito del presente artículo construir una definición de derecho administrativo, razón por la cual hemos tomado para los fines señalados, aquella que consideramos más completa y que como se verá más adelante, se ajusta más a nuestra concepción sobre esta materia.

35 JAIME ORLANDO SANTOFIMIO-GAMBOA, Tratado de derecho administrativo: Introducción a los conceptos de la administración pública y derecho administrativo, Volumen 1, 36 (Editorial Dvinni, Bogotá, 1996). 
36 ALEKSEY HERRERA-ROBLES, Conflictos urbanisticos en Barranquilla, 23 Revista de Derecho, Universidad del Norte, 69-87, 77 (2005).

37 FRANCISCO JAVIER LUCAS-FERNÁNDEZ, Naturaleza, fines y principios generales de la legislación urbanistica. Su influencia en el derecho privado, 3 Revista de Derecho Urbanistico, 14, 15 (1967).

38 EDUARDO GARCÍA DE ENTERRÍA \& LUCIANO PAREJO-ALFONSO, Lecciones de derecho urbanístico, 50 (Editorial Civitas, Madrid, 1979).

39 EDGARDO O. SCOTTI, Contenido, caracteres y principios del derecho urbanistico, en Derecho y planeamiento urbano, 70-104, 75 (CELSO ANTONIO BANDEIRA DE MELLO, RAÚL FRANCISCO NAVAS, RICARDO PABLO RECA, AUGUSTO L. REINHOLD \& EDGARDO O. SCOTTI, Editorial Universidad, Buenos Aires, 1983).

$40 \quad I b ., 82$ a 103.

$41 \quad I b ., 77$.

42 ANTONIO CARCELLER-FERNÁNDEZ, Introducción al derecho urbanistico, 17, 18 (1992).

43 Artículo 8. "Cuando no hay ley exactamente aplicable al caso controvertido, se aplicarán las leyes que regulen casos o materias semejantes, y en su defecto, la doctrina constitucional y las reglas generales de derecho”. Colombia, Ley 153 de 1887, que adiciona y reforma los Códigos nacionales, la ley 61 de 1886 y la 57 de 1887.7.151 Diario Oficial, 28 de agosto de 1887.

44 Artículo 2. “Ámbito de aplicación. Las normas de esta Parte Primera del Código se aplican a todos los organismos y entidades que conforman las ramas del poder público en sus distintos órdenes, sectores y niveles, a los órganos autónomos e independientes del Estado y a los particulares, cuando cumplan funciones administrativas. A todos ellos se les dará el nombre de autoridades (...)". Colombia, Ley 1437 de 2011, por la cual se expide el Código de Procedimiento Administrativo y de lo Contencioso Administrativo. 47.956 Diario Oficial, 18 de enero de 2011.

45 Es importante señalar que el citado artículo 2, en su inciso tercero, señala expresamente que "Las autoridades sujetarán sus actuaciones a los procedimientos que se establecen en este Código, sin perjuicio de los procedimientos regulados en leyes especiales. En lo no previsto en los mismos se aplicarán las disposiciones de este Código”.

46 Cuyas definiciones para efectos del presente artículo fueron expuestas en las notas 8 y 9.

47 Colombia, Corte Constitucional, Sentencia T-508-92, 28 de agosto de 1992, magistrado ponente Fabio Morón-Díaz, acción de tutela de José Joaquín Orozco-Nieto contra la Alcaldía Menor de Engativá.

48 Colombia, Corte Constitucional, Sentencia T-610-92, 14 de diciembre de 1992, magistrado ponente Fabio Morón-Díaz, acción de tutela de Eva Burgos y otros contra el municipio de Bucaramanga.

49 CELSO ANTONIO BANDEIRA DE MELLO, RAÚL FRANCISCO NAVAS, RICARDO PABLO RECA, AUGUSTO L. REINHOLD \& EDGARDO O. SCOTTI, Limites jurídicos de la planificación urbanistica, en Derecho y planeamiento urbano, 429-462, 439-440 (CELSO ANTONIO BANDEIRA DE MELLO, RAÚL FRANCISCO NAVAS, RICARDO PABLO RECA, AUGUSTO L. REINHOLD \& EDGARDO O. SCOTTI, Editorial Universidad, Buenos Aires, 1983).

50 Misma posición presentada en JAIME ORLANDO SANTOFIMIO-GAMBOA (director), Derecho urbanistico. Legislación y jurisprudencia, 41 (2ª ed., Universidad Externado de Colombia, Bogotá, 2009).

51 ADOLFO CARRETERO-PÉREZ, Precisiones sobre urbanismo y derecho urbanistico..., 64 (1974).

52 JOSÉ RAMÓN PARADA-VÁZQUEZ, Derecho urbanistico, 2 (1999).

53 JUAN FELIPE PINILLA-PINEDA, Evolución del sistema urbanistico colombiano: reflexión pendiente desde el Derecho, 5 (Ediciones Uniandes, Bogotá, 2003).

54 Esta misma concepción es presentada por el autor citado, al exponer que el derecho urbanistico está constituido por tres ramas esenciales: la planificación, la gestión y el control. JUAN FELIPE PINILLA-PINEDA \& MAURICIO RENGIFOGARDEAZÁBAL, La ciudad y el derecho, una introducción al derecho urbano contemporáneo, 11 (2012). No obstante lo anterior, consideramos que estas tres "ramas" no son elementos constitutivos de la disciplina estudiada, sino que corresponden 
específicamente al conjunto de herramientas que posee el Estado para intervenir el territorio, en virtud de la función pública del desarrollo territorial.

55 PEDRO PABLO MORCILLO-DOSMAN, Derecho urbanistico colombiano - Historia, normativa y gestión, 494 (Editorial Temis, Bogotá, 2007).

56 ANTONIO CARCELLER-FERNÁNDEZ, Introducción al derecho urbanistico, 17, 18 (1992).

57 JAIME ORLANDO SANTOFIMIO-GAMBOA, Compendio de derecho administrativo, 189-192 (Universidad Externado de Colombia, Bogotá, 2017). LUCIANO PAREJO-ALFONSO, ANTONIO JIMÉNEZ-BLANCO Y CARRILLO \& LUIS ORTEGA-ÁLVAREZ, Manual de derecho administrativo, Volumen 2, 304 ( 5 a ed., Editorial Ariel, Barcelona, 1998).

58 Lo anterior, sin dejar de lado que cada una de las materias objeto de estudio por el derecho urbanistico tiene principios propios que rigen su actividad, como por ejemplo los principios generales de las actuaciones administrativas y los principios especiales que rigen el desarrollo territorial y todas las disciplinas jurídicas que intervienen en esta actividad, en materia tributaria, policiva, entre otras.

59 PEDRO PABLO MORCILLO-DOSMAN, Derecho urbanistico colombiano - Historia..., 137 (2007).

\section{Licencia Creative Commons CC BY 4.0}

Para citar este articulo / To cite this article: ARBOUIN-GÓMEZ, FELIPE, Reflexiones sobre la naturaleza del derecho urbanistico y propuesta de definición, 138 Vniversitas (2019). https://doi.org/10.11144/Javerian a.vj138.rndu 